\title{
Composição e distribuição de macrófitas aquáticas na lagoa da Restinga do Massiambu, Área de Proteção Ambiental Entorno Costeiro, SC
}

\author{
Composition and distribution of aquatic macrophytes in Restinga of Massiambu Lake, \\ Área de Proteção Ambiental Entorno Costeiro, SC
}

\author{
Jonatha Alexandre Andrade Alves ${ }^{1,3}$, Aldaléa Sprada Tavares $^{2} \&$ Rafael Trevisan ${ }^{2}$
}

\begin{abstract}
Resumo
Pesquisas com macrófitas aquáticas têm avançado significativamente no Brasil. Contudo, ainda é reconhecida a necessidade de estudos florísticos, particularmente relacionados à dinâmica da distribuição em lagoas costeiras. O presente estudo avaliou a composição e distribuição de macrófitas aquáticas na Lagoa da Restinga do Massiambu. No período de 2004 a 2007 foram realizados levantamentos da composição, estrutura e formas biológicas das espécies vegetais. Amostras da cobertura vegetal, declividade, nível de água e profundidade máxima foram registradas entre 2006 e 2007. Foram reconhecidas 63 espécies, sendo 48 formas biológicas puras e 15 em combinações. A lagoa revela alta riqueza de espécies, representadas pela ocorrência de táxons inéditos, tanto para área, quanto para o estado. No estudo quantitativo verificou-se maior riqueza de espécies nas zonas mais rasas da lagoa, onde o gradiente e a variação do nível de água criam uma maior diversidade de habitats. A profundidade mostrou-se um bom preditor da diversidade e riqueza de espécies. A declividade e a estrutura da comunidade estão associadas, modificando-se conjuntamente. As espécies possuem uma amplitude de ocorrência, tendendo a desenvolver maior cobertura em profundidades preferenciais. A distribuição da estrutura e composição das macrófitas aquáticas descreveram padrões espaciais que são corroborados em outros estudos similares para ambientes lacustres de águas rasas. Palavras-chave: lagoa costeira rasa; macrófitas aquáticas; profundidade preferencial; padrões espaciais; estrutura da comunidade.
\end{abstract}

\begin{abstract}
Research on aquatic macrophytes has advanced significantly in Brazil, however, there is still a need for floristic studies, particularly related to the dynamic distribution in coastal lakes. This study assessed the composition and distribution of macrophytes in Lake Restinga Massiambu. From 2004 to 2007 surveys were done to characterize the composition, structure and life forms of plant species. Samples of cover vegetation, slope, water level and maximum depth were recorded in 2006 and 2007. A total of 63 species were identified, including 48 pure life forms and 15 in combination. The lake had high species richness represented by the occurrence of new taxa in both the area and statewide. In the quantitative study there was greater richness in the shallower zones of the lake, where the gradient and the change of the water level create a greater diversity of habitats. The depth showed to a good predictor of diversity and richness. The slope and community structure are associated, changing together. The species have amplitude of occurrence tending to develop greater coverage in preferential depth. The distribution of the composition and structure of the macrophytes described spatial patterns, which can be corroborated in other studies of shallow lakes.
\end{abstract}

Key words: shallow costal lake; aquatic macrophytes; preferential depth; spatial patterns; community structure.

\footnotetext{
${ }^{1}$ Universidade Federal de Santa Catarina, Centro de Ciências Biológicas, Programa de Pós-Graduação em Biologia Vegetal, Trindade, 88040-970, Florianópolis, SC, Brasil.

${ }^{2}$ Universidade Federal de Santa Catarina, Centro de Ciências Biológicas, Depto. Botânica, Trindade, 88040-970, Florianópolis, SC, Brasil.

${ }^{3}$ Autor para correspondência: jonathaalves@gmail.com
} 


\section{Introdução}

A terminologia adotada para vegetais que habitam ambientes aquáticos é bastante diversificada. Cook et al. (1974) designam como macrófitas de água doce, todas as Charophyta, Bryophyta, Pterodophyta e Spermatophyta, cujas partes fotossintetizantes ativas estão permanentemente, ou por diversos meses, todos os anos, submersas ou flutuantes na superfície da água. Irgang \& Gastal Jr. (1996) incluem neste conceito as espécies de ambientes salobros.

Do ponto de vista taxonômico, 42 famílias de dicotiledôneas, 30 de monocotiledôneas, 17 de briófitas e seis de pteridófitas, apresentam exemplares de plantas aquáticas (Esteves 1998a). Independentes da heterogeneidade filogenética e taxonômica, esses vegetais apresentam uma classificação ecológica ou forma biológica que reflete sua adaptação ao meio aquático.

Segundo Esteves (1998a), os principais grupos de macrófitas aquáticas quanto ao seu biótipo, denominados genericamente de grupos ecológicos são: emersas, com folhas flutuantes, submersas enraizadas, submersas livres e flutuantes. Outros autores (Pott et al. 1989; Pedralli \& Gonçalves 1997; Pott \& Pott 2000b) utilizam o termo forma biológica para classificar as macrófitas aquáticas, substituindo os termos acima por espécies emergentes, submersas fixas, submersas livres, flutuantes fixas e flutuantes livres, acrescentando a essa terminologia, as anfíbias e as epífitas.

No Brasil foram realizados trabalhos sobre a composição florística de macrófitas aquáticas para os Estados do Rio Grande do Sul (Irgang et al. 1984; Irgang \& Gastal Jr. 1996; Rolon \& Maltchik 2006), Paraná (Thomaz et al. 2002; Kita \& Souza 2003; Santos \& Thomaz 2007), São Paulo (Amaral et al. 2008), Minas Gerais (Pedralli \& Gonçalves 1997; Pivari et al. 2008; Ferreira et al. 2010), Rio de Janeiro (Bove et al. 2003; Paz \& Bove 2007), Mato Grosso e Mato Grosso do Sul (Pott et al. 1989; Pott \& Pott 2000a; Rocha et al. 2007), Bahia (França et al. 2003; Neves et al. 2006), Ceará (Matias et al. 2003), Amapá (Costa Neto et al. 2003; 2007) e Amazonas (Albuquerque 1981; Walker et al, 1999) abordando, dentre outros, ambientes lacustres.

Para Santa Catarina, alguns pesquisadores realizaram inventários florísticos, incluindo plantas aquáticas (Rambo 1949; Reitz 1961; Falkenberg 1999). A Flora Ilustrada Catarinense, publicada desde 1965, apresenta diversos fascículos incluindo espécies aquáticas. Para a Baixada do Massiambu, Tavares et. al. (2007) apresentaram uma listagem das plantas aquáticas e paludosas de Cyperaceae.

A necessidade de um melhor conhecimento sobre a composição e estrutura florística destes ambientes no Estado de Santa Catarina, decorre da carência de estudos com enfoque em macrófitas aquáticas. Esteves (1998b) afirma que nenhuma comunidade límnica foi tão negligenciada no âmbito das pesquisas, quanto àquelas formadas por macrófitas aquáticas.

Alguns estudos tratam de parâmetros fitossociológicos associados a levantamentos florísticos em ambientes aquáticos (Pott et al.1992; Matias et al. 2003; Neves et al. 2006). Outros utilizam a fitossociologia para avaliar as mudanças na estrutura e composição de plantas aquáticas (Fortney et al. 2004; Rebellato \& Nunes da Cunha 2005; Ferreira et al. 2010). Contudo, ainda são poucos os trabalhos que abordam a dinâmica e a estrutura de comunidades de macrófitas aquáticas em comparação aos realizados sobre fitossociologia para os ecossistemas terrestres (Ferreira et al. 2010). Diversos autores (Spence 1982; Fernández-Aláez et al. 1999; Maltchik et al. 2007) têm inferido sobre a influência do regime de água e da profundidade sobre o crescimento e distribuição de plantas em áreas alagadas. A variação no nível de água constitui um fator que afeta simultaneamente todos os bancos de macrófitas, servindo para explicar as alterações da vegetação que ocorrem em um mesmo ambiente (Thomaz et al. 2005; Thomaz 2005).

Apesar do avanço das pesquisas com essas plantas no Brasil, ainda é reconhecida a necessidade de estudos básicos, particularmente relacionados com a determinação de sua amplitude ecológica quando submetidas a diferentes fatores ambientais (Pompêo \& Moschini-Carlos 2003; Thomaz \& Bini 2003). Os estudos existentes não condizem com a grande diversidade de espécies que vegetam em ambientes aquáticos (Bove et al. 2003), tampouco com a dinâmica de colonização e distribuição desses táxons em lagoas costeiras.

O presente estudo objetivou avaliar padrões espaciais da variação do nível de água, relacionando-os à estrutura, distribuição e composição de macrófitas aquáticas em uma lagoa da Área de Proteção Ambiental do Entorno Costeiro de Santa Catarina. 
Material e Métodos

Área de estudos

A Área de Proteção Ambiental (APA) do Entorno Costeiro integra o mosaico de Unidades de Conservação da Serra do Tabuleiro e Terras do Massiambu do estado de Santa Catarina. Abrangendo os Municípios de Garopaba, Paulo Lopes, Palhoça e Florianópolis, entre as coordenadas geográficas de $27^{\circ} 49^{\prime} 54,77880^{\prime}$ 'S e $28^{\circ} 00^{\prime} 33,99107^{\prime}$ 'S e de 48 34' 18,65207' 'W e 48 37'45,65138''W, a APA possui uma área total de aproximadamente 5.260 hectares (Santa Catarina 2009).

A área de estudo compreende a Lagoa da Restinga do Massiambu (Fig. 1) localizada na APA do Entorno Costeiro, sendo o único ambiente lacustre das Terras do Massiambu (também denominada, Baixada do Massiambu) que mantém a sua estrutura ecológica praticamente intacta. Essa lagoa apresenta seu regime de água regulado pela precipitação pluvial, sendo mantida pelo afloramento de lençol freático durante as estações áridas, podendo ser considerada rasa devido a sua profundidade não ultrapassar 1,5 m. Segundo Reitz (1961), na Baixada do Massiambu, predominam ambientes de água doce cobertos por vegetações de restinga.

\section{Levantamento florístico \\ e fitossociológico}

O levantamento florístico foi realizado entre os anos de 2004 e 2007 através de caminhadas às margens e navegações na lagoa, procurando cobrir diferentes estações do ano, trimestralmente. Foram coletadas amostras férteis seguidas de prensagem, secagem e herborização. Algumas espécies foram coletadas estéreis e levadas ao laboratório para cultivo, acompanhamento da floração e posterior identificação.

Para a identificação das espécies, foram utilizadas bibliografias especializadas (Pilz \& Pereira 1988; Irgang \& Gastal Jr. 1996; Guglieri \& LonghiWagner 2000; Pott \& Pott 2000b; Prado 2003; Mondin 2004; Trevisan \& Boldrini 2008; Souza \& Giulietti 2009) e materiais depositados no Herbário do Departamento de Botânica da Universidade Federal de Santa Catarina, sigla FLOR. Os sistemas de classificação adotados foram: para as fanerógamas o APG III (2009); para Pteridophyta o de Tryon \& Tryon (1982) e para Characeae o de Wood \& Imahori (1964, 1965). Todo o material testemunho foi incorporado no Herbário FLOR.
Para o levantamento fitossociológico foram pré-selecionadas áreas às margens da lagoa que apresentassem inundações durante os eventos de chuva ao longo do ano. Posteriormente foi realizado sorteio aleatório de três locais alagáveis para colocação de um transecto permanente, sentido margem-centro, iniciando em áreas de solo hidromórficos, marcados pela existência de plantas tipicamente aquáticas.

De agosto de 2006 a agosto de 2007 foram registrados todos os meses, o nível de água e a cobertura vegetal para cada espécie em um quadro de $0,25 \mathrm{~m}^{2}$, estabelecido a cada $1 \mathrm{~m}$ nos transectos, totalizando 400 unidades amostrais. Anotações sobre a profundidade máxima e a declividade total do transecto, também foram registradas. A declividade total foi gerada a partir da fórmula DT = " $\mathrm{H} / \mathrm{L}$; onde: " $\mathrm{H}=$ diferença entre os níveis de água mais distantes e $\mathrm{L}=$ comprimento do transecto. $\mathrm{Na}$ estimativa do nível de água do quadro e profundidade máxima do transecto utilizou-se uma régua limnimétrica. As amostragens nas regiões mais profundas foram realizadas com um quadro de cano perfurado de PVC, contrastando seu limite com o sedimento e as espécies. Nas regiões mais rasas, utilizou-se um quadro flutuador de madeira. Uma pequena amostra de cada banco de Characeae foi retirada, quando necessário, para confirmação da espécie.

Para estimar a cobertura vegetal foi utilizada a escala de Domin transformada (Bannister 1966), que combina as relações entre a cobertura (percentual que cada táxon ocupa dentro da amostra) e a frequiência (probabilidade ou chance de uma espécie ser encontrada na amostra). O grau da cobertura de cada espécie foi estimado independentemente das outras, de tal forma que os valores de cobertura de todas as espécies juntas pudessem exceder $100 \%$ (Pakarinem 1984).

O reconhecimento das formas biológicas no levantamento florístico e fitossociológico foi realizado por observações ao longo de todo o período de estudo, considerando as adaptações dos táxons às variações de nível da água e à distribuição de crescimento da cobertura vegetal registrada no estudo quantitativo. A classificação ecológica das macrófitas aquáticas seguiu Pedralli \& Gonçalves (1997)e Pott \& Pott (2003).

\section{Análise dos dados}

A partir dos dados de composição florística e de cobertura vegetal, foram calculados os parâmetros fitossociológicos de frequência absoluta $(F A=100 . a / P T)$, frequência relativa $(F R=100 . F A /$ 

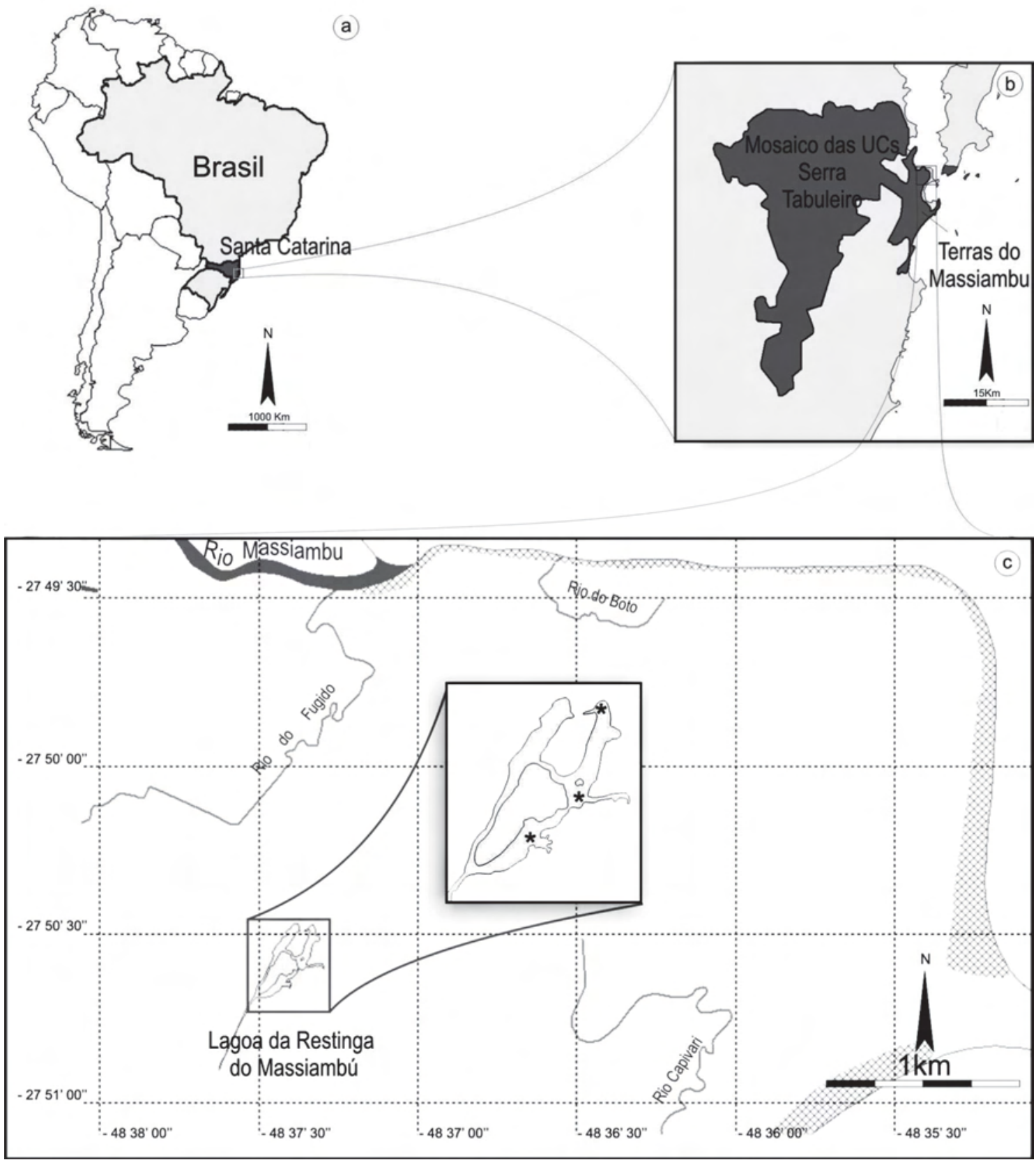

Figura 1 - Localização da área de estudo - a. estado de Santa Catarina; b. mosaico de Unidades de Conservação da Serra do Tabuleiro e Terras do Massiambu; c. lagoa da Restinga do Massiambu com destaque para as áreas de amostragem fitossociológica (*).

Figure 1 - Location of the study area - a. State of Santa Catarina; b. mosaic of Conservation of the Serra of the Tabuleiro and Terras of the Massiambu; c. lake on the Restinga of the Massiambu with phytosociological sampling areas (*).

SFA), valor de cobertura $(\mathrm{VC}=100 . \mathrm{SCV} / \mathrm{PT}) \mathrm{e}$ cobertura relativa $(\mathrm{CR}=100 . \mathrm{VC} / \mathrm{SVC})$, segundo Braun-Blanquet (1979); onde: $\mathrm{a}_{\mathrm{i}}=$ amostra com a espécie $\mathrm{i} ; \mathrm{PT}=$ número total de parcelas e $\mathrm{CV}_{\mathrm{i}}=$ cobertura vegetal para a espécie $\mathrm{i}$, adaptada à média de Domin transformado (Bannister 1966).
Para cada transecção foram estimadas a riqueza de espécies ( $\mathrm{S}$ ) definida simplesmente como o total de táxons ocorrentes (Peet 1974), o índice de diversidade de Shannon [H' $\left.=-\mathrm{S}\left(\mathrm{n}_{\mathrm{i}} / \mathrm{N}\right) \log _{2}\left(\mathrm{n}_{\mathrm{i}} / \mathrm{N}\right)\right]$, que atribui maior peso às espécies raras e o índice de equitabilidade $\left[\mathrm{J}=\mathrm{H}^{\prime} / \mathrm{Hmáx}\right]$; sendo $\mathrm{n}_{\mathrm{i}}=$ valor 
de importância (dado pelo VCi) para cada espécie e $\mathrm{N}=$ total de valores de cobertura para todas as espécies na amostra. Análises de correlação de Pearson (r) foram realizadas para os dados de profundidade máxima e declividade, relacionados com a riqueza de espécies e a diversidade, procurando reconhecer a existência de padrões na estrutura da comunidade. A utilização dos métodos estatísticos paramétricos requereu a verificação da normalidade das distribuições através do teste Shapiro-Wilk e a análise de simetria e curtose dado pelo teste D'AgostinoPearson (Ayres et al. 2007).

Histogramas de distribuição da cobertura relativa das espécies mais frequentes por zonas de profundidade de água, foram elaborados para verificar padrões no seu desenvolvimento. Com os dados de cobertura vegetal foi feita uma análise de correspondência destendenciada (DCA) para verificar a existência de um gradiente na distribuição das espécies. Quando foram detectadas tendências paralelas aos eixos do DCA, utilizou-se a análise de correlação de Spearman (rs), objetivando explorar esta relação (Kent \& Cooker 1992).

Para as rotinas das análises de correlação de Pearson e correlação de Spearman, utilizou-se o programa BioEstat 5.0 (Ayres et al. 2007). Já os cálculos de diversidade e equitabilidade foi realizado com MVSP versão 3.1 (Kovacs 1999) e a análise multivariada através do PC-ORD v3.15 for Windows (McCune \& Mefford 1999).

\section{Resultados e Discussão}

\section{Levantamento florístico}

No levantamento florístico da Lagoa da Restinga do Massiambu foi possível reconhecer 33 famílias, 44 gêneros e 63 espécies, distribuídas em Carophyta (3), Pteridophyta (1 - Azolla filiculoides Lam.) e Angiospermae (59) (Tab. 1).

Comparando este estudo com diversos trabalhos realizados no Brasil (Pott et al. 1989; Pedralli \& Gonçalves 1997; Thomaz et al. 2002; Kita \& Souza 2003; Matias et al. 2003; Neves et al. 2006; Rolon \& Maltchik 2006; Paz \& Bove 2007; Rocha et al. 2007; Santos \& Thomaz 2007; Pivari et al. 2008; Ferreira et al. 2010), o número de espécies de macrófitas aquáticas encontradas para a lagoa pode ser considerado expressivo, considerando um único ambiente.

A Baixada do Massiambu, juntamente com as demais áreas de restinga de Santa Catarina, está incluída na planície quartenária da Região Sul, sendo uma das maiores em número de táxons vasculares no Brasil (Falkenberg 1999), justificando a riqueza de espécies da lagoa. Além disso, Reitz (1961) afirma que a restinga da Baixada do Massiambu é uma das mais ricas em espécies na zona marítima catarinense.

Dentre as famílias com maior representatividade na área, destacam-se Cyperaceae (8) e Polygonaceae (5), as demais apresentam uma à três espécies. Cyperaceae também apresentou o maior número de espécies nos estudos desenvolvidos por Bove et al. (2003), Rebellato \& Nunes da Cunha (2005) e Ferreira et al. (2010). Em um levantamento realizado para Cyperaceae, Tavares et al. (2007) reconheceram 33 espécies para diferentes áreas úmidas da Baixada do Massiambu. De acordo com Goetghebeur (1998) essa família tende a dominar esses ambientes, devido à presença de rizomas, tubérculos e estolões, que lhes permitem maior eficiência na propagação vegetativa. Além disso, seus representantes são perenes, dominando completamente o ambiente no período de redução da coluna d'água (Bove et al. 2003).

Polygonaceae está representada pelo gênero Polygonum L., com cinco espécies presentes durante todo o ano. Embora um número relativamente pequeno de espécies dessa família ocorra em nossa flora, representantes de Polygonum são frequentemente encontrados em áreas alagáveis (Souza \& Lorenzi 2008). A abundante produção de sementes e a propagação vegetativa por enraizamento dos nós justificam sua presença nesses locais (Pott \& Pott 2000b).

Dos táxons identificados, Echinodorus bolivianus, Lilaeopsis attenuata, Hydrocotyle verticillata, Eclipta prostrata, Enydra sessilis, Chara guairensis, C. rusbyana, C. zeylanica, Eleocharis bicolor, Eleocharis sp., Ludwigia peploides, Polygonum meisnerianum, $P$. portoricense, $P$. punctatum, Potamogeton pectinatus, Heteranthera reniformes, Bacopa australis e Gratiola peruviana, são tidos como novos registros de ocorrência para o mosaico de Unidades de Conservação da Serra do Tabuleiro e Terras do Massiambu.

Até o momento do estudo, somente Chara rusbyana era conhecida para Santa Catarina (Bicudo 1972). No que diz respeito aos demais representantes da família, $C$. guairensis apresenta registro para o Rio Grande Sul (Prado 2003), Mato Grosso do Sul (Bueno et al. 1996), Mato Grosso (Bueno et al. 2009), Paraná (Bicudo 1972; 1974) e São Paulo (Vieira Jr. et al. 2003; Picelli-Vicentim et al. 2004). Já C. zeylanica ocorre no Espírito Santo 
Tabela 1 - Famílias e espécies reconhecidas na Lagoa da Restinga do Massiambu e suas respectivas formas biológicas. Table 1 - Families and species recognized in Lake on the Restinga do Massiambu and their biological forms.

\begin{tabular}{|c|c|c|}
\hline Família & Espécies & Forma biológica \\
\hline Acanthaceae & Hygrophila costata Nees & Anfíbia \\
\hline Amaryllidaceae & Crinum americanum $\mathrm{L}$. & Anfíbia \\
\hline Alismataceae & Echinodorus bolivianus (Rusby) Holm-Niels. & Anfíbia \\
\hline Apiaceae & $\begin{array}{l}\text { Centella asiatica }(\mathrm{L} .) \text { Urban. } \\
\text { Lilaeopsis attenuata (Hook. \& Arn.) Fernald }\end{array}$ & $\begin{array}{l}\text { Anfíbia } \\
\text { Emergente }\end{array}$ \\
\hline Araceae & Lemna valdiviana Phil. & Flutuante livre \\
\hline Araliaceae & $\begin{array}{l}\text { Hydrocotyle ranunculoides L.f } \\
\text { Hydrocotyle verticillata Thunb. }\end{array}$ & $\begin{array}{l}\text { Emergente e Flutuante Fixa } \\
\text { Anfíbia }\end{array}$ \\
\hline Asteraceae & $\begin{array}{l}\text { Eclipta prostrata }(\mathrm{L} .) \text { L. } \\
\text { Enydra sessilis }(\mathrm{Sw} .) \mathrm{DC} . \\
\text { Bidens laevis }(\mathrm{L} .) \text { Britton, Sterns \& Poggenb. }\end{array}$ & $\begin{array}{l}\text { Anfíbia } \\
\text { Anfíbia e Emergente } \\
\text { Anfíbia }\end{array}$ \\
\hline Azollaceae & Azolla filiculoides Lam. & Flutuante livre \\
\hline Begoniaceae & Begonia fischeri Schrank & Anfíbia \\
\hline Campanulaceae & Lobelia nummularioides Cham. & Anfíbia \\
\hline Characeae & $\begin{array}{l}\text { Chara guairensis } \mathrm{R} . \text { Bic. } \\
\text { Chara rusbyana Howe } \\
\text { Chara zeylanica Klein } \text { ex Willd }\end{array}$ & $\begin{array}{l}\text { Submersa fixa } \\
\text { Submersa fixa } \\
\text { Submersa fixa }\end{array}$ \\
\hline Commelinaceae & $\begin{array}{l}\text { Commelina difusa Burn } \\
\text { Floscopa glabrata (Kunth) Hassk. }\end{array}$ & $\begin{array}{l}\text { Anfíbia } \\
\text { Anfíbia }\end{array}$ \\
\hline Cyperaceae & $\begin{array}{l}\text { Cladium mariscus (L.) Pohl. } \\
\text { Eleocharis bicolor (Chapm.) } \\
\text { Eleocharis flavescens (Poir.) Urb. } \\
\text { Eleocharis minima Kunth } \\
\text { Eleocharis nana Kunth } \\
\text { Eleocharis sp. } \\
\text { Pycreus lanceolatus (Poir.) C.B. Clarke } \\
\text { Rhynchospora legrandii Kük. in Barros }\end{array}$ & $\begin{array}{l}\text { Anfíbia } \\
\text { Anfíbia } \\
\text { Anfíbia e Emergente } \\
\text { Anfíbia } \\
\text { Anfíbia } \\
\text { Emergente } \\
\text { Anfíbia } \\
\text { Anfíbia }\end{array}$ \\
\hline Eriocaulaceae & $\begin{array}{l}\text { Eriocaulon magnificum Ruhl. } \\
\text { Eriocaulon modestum Kunth. }\end{array}$ & $\begin{array}{l}\text { Anfíbia } \\
\text { Anfíbia }\end{array}$ \\
\hline Fabaceae & $\begin{array}{l}\text { Desmodium adscendens (Sw.) DC. } \\
\text { Stylosanthes viscosa }(\mathrm{L} .) \text { Sw. }\end{array}$ & $\begin{array}{l}\text { Anfíbia ocasional } \\
\text { Anfíbia ocasional }\end{array}$ \\
\hline Juncaceae & Juncus microcephalus Kunth & Anfíbia e Emergente \\
\hline Lamiaceae & Hyptis brevipes Poit. & Emergente \\
\hline Lentibulariaceae & $\begin{array}{l}\text { Utricularia gibba } \mathrm{L} . \\
\text { Utricularia tricolor St.-Hil. }\end{array}$ & $\begin{array}{l}\text { Anfíbia e Epífita } \\
\text { Anfíbia e Emergente }\end{array}$ \\
\hline Linderniaceae & Lindernia rotundifolia (L.) Alston & Anfíbia \\
\hline Lythraceae & $\begin{array}{l}\text { Cuphea aperta Koehne } \\
\text { Cuphea carthagenensis (Jacq.) J. F. Macbr. }\end{array}$ & $\begin{array}{l}\text { Anfíbia } \\
\text { Anfíbia }\end{array}$ \\
\hline Mayacaceae & Mayaca fluviatilis Aubl. & Anfíbia, Emergente e Submersa fixa \\
\hline
\end{tabular}




\begin{tabular}{|c|c|c|}
\hline Família & Espécies & Forma biológica \\
\hline Melastomataceae & $\begin{array}{l}\text { Acisanthera alsinaefolia (DC.) Triana } \\
\text { Tibouchina urvilleana (DC.) Cogn. }\end{array}$ & $\begin{array}{l}\text { Anfíbia } \\
\text { Anfíbia ocasional }\end{array}$ \\
\hline Menyanthaceae & Nymphoides indica (L.) Kuntze & Anfíbia e Flutuante fixa \\
\hline Ochnaceae & Sauvagesia erecta $\mathrm{L}$. & Anfíbia \\
\hline Onagraceae & $\begin{array}{l}\text { Ludwigia octovalvis (Jacq.) P.H. Raven } \\
\text { Ludwigia lagunae (Morong) Hara } \\
\text { Ludwigia peploides (Kunth) Raven }\end{array}$ & $\begin{array}{l}\text { Anfíbia } \\
\text { Anfíbia } \\
\text { Anfíbia, Emergente e Flutuante fixa }\end{array}$ \\
\hline Poaceae & $\begin{array}{l}\text { Luziola peruviana Juss. Ex J.F. Gmel. } \\
\text { Panicum schwackeanum Mez. } \\
\text { Panicum polygonatum Schrad. }\end{array}$ & $\begin{array}{l}\text { Anfíbia e Emergente } \\
\text { Anfíbia } \\
\text { Anfíbia }\end{array}$ \\
\hline Polygalaceae & Polygala paniculata $\mathrm{L}$. & Anfíbia \\
\hline Polygonaceae & $\begin{array}{l}\text { Polygonum hydropiperoides Michx. } \\
\text { Polygonum meisnerianum Cham. \& Schltdl. }\end{array}$ & $\begin{array}{l}\text { Anfíbia e Emergente } \\
\text { Emergente }\end{array}$ \\
\hline Polygonaceae & $\begin{array}{l}\text { Polygonum persicarioides Kunth } \\
\text { Polygonum portoricense Bertero ex Endl. } \\
\text { Polygonum punctatum Elliott }\end{array}$ & $\begin{array}{l}\text { Anfíbia e Emergente } \\
\text { Emergente } \\
\text { Anfíbia e Emergente }\end{array}$ \\
\hline Potamogetonaceae & $\begin{array}{l}\text { Potamogeton lucens } \mathrm{L} . \\
\text { Potamogeton pectinatus } \mathrm{L} .\end{array}$ & $\begin{array}{l}\text { Submersa fixa } \\
\text { Submersa fixa }\end{array}$ \\
\hline Pontederiaceae & Heteranthera reniformes Ruiz \& Pav. & Emergente \\
\hline Rubiaceae & $\begin{array}{l}\text { Diodia saponariifolia (Cham. \& Schltdl.) } \\
\text { K. Schum. }\end{array}$ & Emergente \\
\hline Scrophulariaceae & $\begin{array}{l}\text { Bacopa monnieri }(\mathrm{L} .) \text { Wettst. } \\
\text { Bacopa australis V.C.Souza } \\
\text { Gratiola peruviana L. }\end{array}$ & $\begin{array}{l}\text { Anfíbia, Emergente e Submersa Fixa } \\
\text { Anfíbia } \\
\text { Anfíbia e Emergente }\end{array}$ \\
\hline Xyridaceae & Xyris jupicai L. C. Rich. & Anfíbia \\
\hline
\end{tabular}

(Bicudo, 1972; 1974), Pará (Rodrigues 1964), Pernambuco (Wood \& Imahori 1965), Rio Grande do Sul (Prado 2003), Mato Grosso e Mato Grosso do Sul (Araújo et al. 2010). A ocorrência das espécies $C$. guairensis e $C$. zeylanica se constituem em novas citações para o estado de Santa Catarina.

Algumas das espécies identificadas na lagoa foram descritas por Falkenberg (1999) como sendo um dos elementos mais importantes para a fitofisionomia de restinga herbácea/arbustiva de lagunas, banhados e baixadas, destacando-se: Acisanthera alsinaefolia, Utricularia tricolor, Eriocaulon magnificum, E. modestum, Cladium jamaicense, Cuphea aperta, Bacopa monnieri, Nymphoides indica e Mayaca fluviatilis.

Cuphea aperta é uma espécie endêmica, sendo considerada rara ou ameaçada de extinção para Santa Catarina (Klein 1996). O registro desse táxon, assim como o não registro de espécies exóticas na área estudada, demonstra a importância para a conservação da lagoa e do seu entorno.

Durante os meses áridos ao longo deste estudo, muitas espécies frequentemente observadas na lagoa reduziram suas populações chegando a desaparecer, como por exemplo, Utricularia tricolor, coletada apenas no início do estudo, não sendo mais registrada após o período de baixa precipitação. Este comportamento de $U$. tricolor foi observado também por Bove et al. (2003). Por outro lado, com o aumento da precipitação e a consequente elevação do nível de água na lagoa, novas espécies foram registradas, como Azolla filiculoides, Chara guairensis, Lemna valdiviana e Potamogeton pectinatus. 
A análise da composição florística da Lagoa da Restinga do Massiambu, revela uma alta riqueza de espécies, sendo representada por táxons inéditos, tanto para a área estudada, quanto para o Estado, contribuindo efetivamente para o conhecimento da composição e diversidade de macrófitas aquáticas em Santa Catarina.

\section{Distribuição da estrutura} das macrófitas aquáticas

A riqueza de espécies foi maior na zona marginal da lagoa, onde os níveis de água são mais baixos (Fig. 2). Esse padrão é reconhecido para alguns lagos tropicais (Collot et al. 1983; Pott et al. 1989; Fortney et al. 2004) e temperados (Keddy 1983, 1984; Fernández-Aláez et al. 1986). As zonas marginais da lagoa são regiões de águas rasas, onde a variação no nível de água é mais intensa do que nas demais, refletindo no aumento da riqueza de espécies (Fortney et al. 2004). Além disso, essas zonas constituem uma região de interface entre o ambiente aquático e o terrestre, proporcionando um habitat heterogêneo que frequentemente apresenta relações positivas com a diversidade (Barreto 1999).

A maior riqueza encontrada nestes locais pode ser também atribuída à ocorrência de espécies anfíbias e emergentes, que juntas representam $74,6 \%$ da composição florística de macrófitas aquáticas na lagoa estudada. A dominância dessas

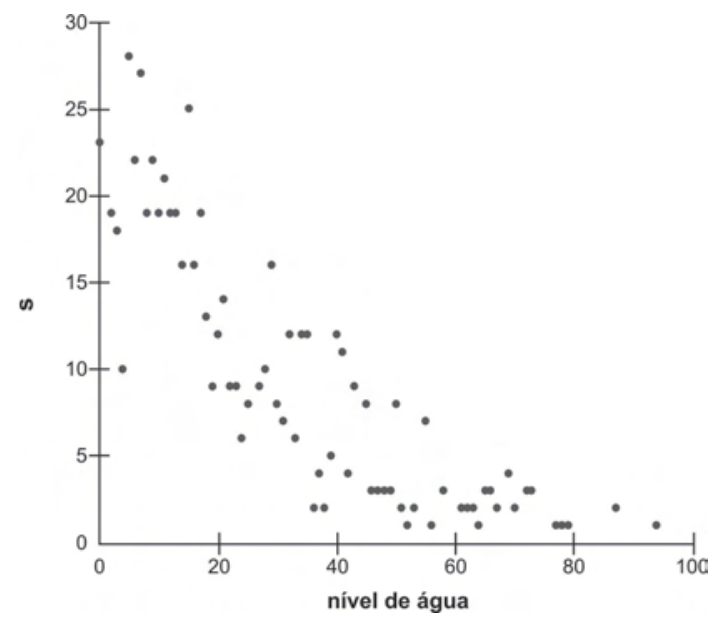

Figura 2 - Diagrama de dispersão entre nível de água (cm) da lagoa da Restinga do Massiambu e a riqueza de espécies (S) de macrófitas aquáticas.

Figure 2 - Dispersal diagram between water level $(\mathrm{cm})$ from the lake on the Restinga of the Massiambu and the species richness (S) of aquatic macrophytes formas de vida está associada a ambientes sujeitos às inundações sazonais, baixa profundidade e resistência das espécies à diminuição do volume de água (Neves et al. 2006; Costa Neto et al. 2007).

O aumento da profundidade máxima contribuiu positivamente para a riqueza de espécies (Fig. 3a) sendo significativamente correlacionados $(\mathrm{r}=$ $0,4102 ; \mathrm{p}<0,03)$.

Com o acréscimo do nível de água, muitas áreas úmidas adjacentes à lagoa foram inundadas, possivelmente recrutando bancos de sementes e propágulos vegetativos, favorecendo o desenvolvimento de novas espécies. Além disso, a elevação do nível de água amplia e/ou cria novos habitats proporcionando maior heterogeneidade espacial, também refletindo positivamente sobre o índice de diversidade (Fig. 3b), processo também descrito por Fernández-Aláez et al. (1999). Em contra partida, a redução da riqueza de espécies e da diversidade durante baixos níveis de água é causada pela contração dos habitats aquáticos (Santos \& Thomaz 2007), que pode ser reconhecida durante a diminuição da profundidade máxima da lagoa.

Não somente a profundidade, mas também a declividade refletiu positivamente com a riqueza de espécies e a diversidade (Fig. 3c-d). A maior declividade da região litorânea elevou a coluna de água da lagoa, favorecendo a colonização de macrófitas aquáticas de diferentes formas biológicas. Santos \& Thomaz (2007) relatam que a declividade da região litorânea apresenta relações significativas com o comprimento dos transectos e a riqueza de espécies, sugerindo, indiretamente, que a declividade pode ser um fator importante para determinar a riqueza de macrófitas aquáticas.

Notadamente, a alta precipitação e consequente elevação do nível de água, promoveram variações na região litorânea, alterando declividade da lagoa. Mudanças na topografia alteram a dinâmica do litoral (Duarte \& Kalff 1986) contribuindo para heterogeneidade do ambiente, que frequentemente apresenta relação positiva com a diversidade (Barreto 1999).

$\mathrm{O}$ sentido das relações entre riqueza de espécies e a declividade da região litorânea é apresentado negativamente em alguns trabalhos, ou seja, uma maior riqueza de espécies é encontrada em menor declividade, porém esta relação nem sempre é significativa (Souza et al. 2002; Santos \& Thomaz 2007). A relação positiva encontrada no estudo pode ser devido a baixa declividade $(0,1>$ $0,6 \mathrm{~m} / \mathrm{m}$ ) apresentada pela lagoa. 

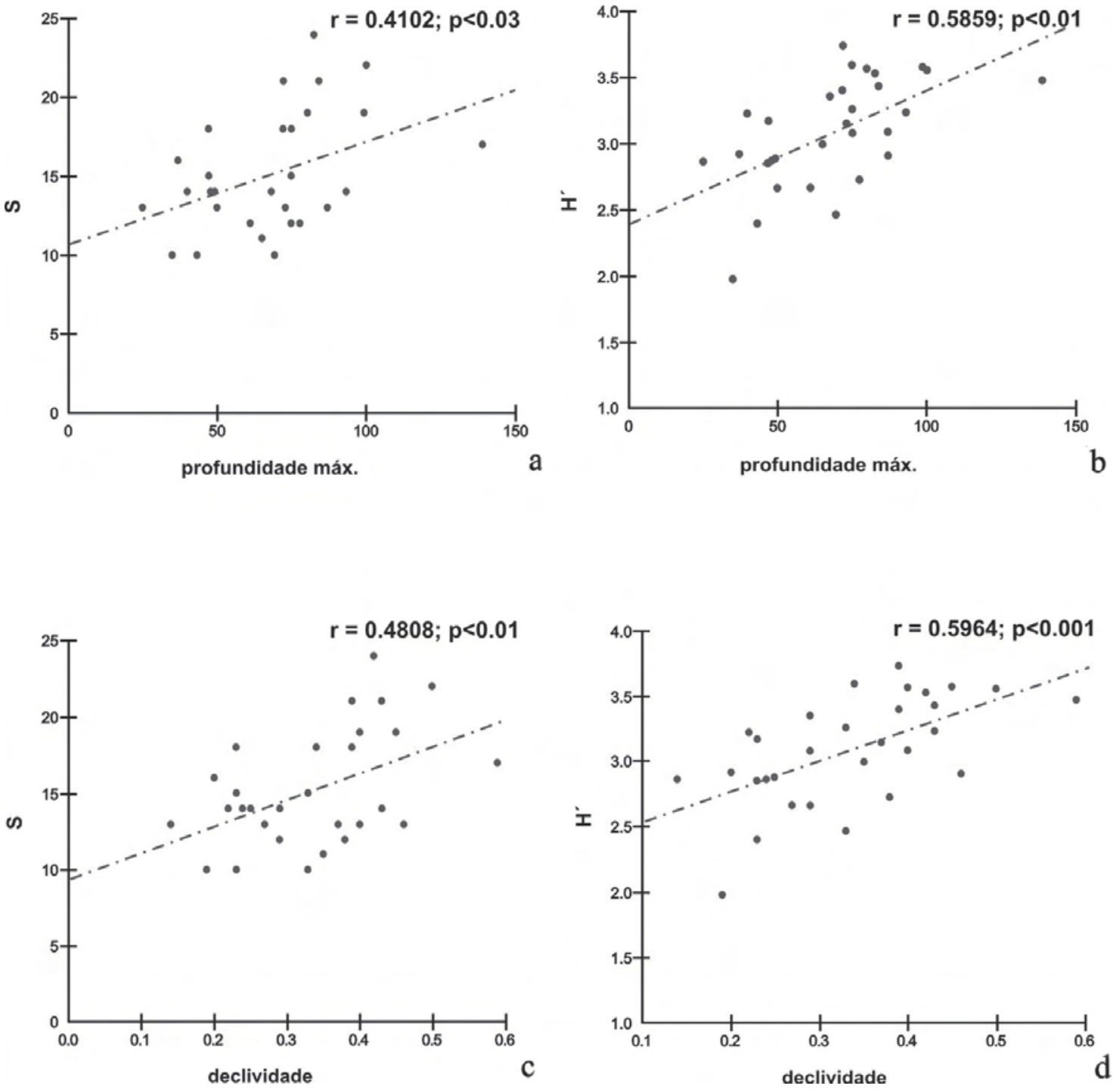

Figura 3 - Distribuição de macrófitas aquáticas da Lagoa de Massiambu. Correlações entre: a. riqueza de espécies (S) e a profundidade máxima da lagoa $(\mathrm{cm})$; b. diversidade $\left(\mathrm{H}^{\prime}\right)$ e a profundidade máxima $(\mathrm{cm})$; c. riqueza de espécies (S) e a declividade $\left(\mathrm{m} . \mathrm{m}^{-1}\right)$; d. a diversidade $\left(\mathrm{H}^{\prime}\right)$ e a declividade $\left(\mathrm{m} / \mathrm{m}^{-1}\right)$.

Figure 3 - Distribution of aquatic macrophytas from the Massiambu Lake. Correlations between: a. species richness (S) and maximum depth of the lake $(\mathrm{cm})$; b. diversity $\left(\mathrm{H}^{\prime}\right)$ and maximum depth $(\mathrm{cm})$; c. species richness $(\mathrm{S})$ and slope $\left(\mathrm{m} / \mathrm{m}^{-1}\right)$; d. diversity (H') and slope $\left(\mathrm{m} \cdot \mathrm{m}^{-1}\right)$.

Reconhecida a significância e a direção da relação entre a riqueza de macrófitas aquáticas e a declividade, espera-se uma resposta similar quanto à diversidade, uma vez que o índice de Shannon aumenta com a adição de espécies (Krebs 1998).

A análise da distribuição da estrutura das macrófitas aquáticas ocorrentes na Lagoa da Restinga do Massiambu evidencia um padrão de zonação, onde a maior riqueza de espécies ocorre na zona marginal da lagoa. Nessas regiões, o gradiente e a variação do nível de água criam uma diversidade de habitats, que reflete na alta riqueza de espécies (Fortney et al. 2004).

A profundidade pode ser considerada um bom preditor da diversidade e riqueza de espécies, com ampliação ou contração dos habitats aquáticos. De forma similar, a variação da declividade altera a dinâmica do litoral, gerando maior heterogeneidade espacial, refletindo positivamente na estrutura da comunidade. 
Formas biológicas e a distribuição espacial das macrófitas aquáticas

Dentre as formas biológicas reconhecidas na lagoa, destacam-se as anfíbias, por apresentarem a maior riqueza de táxons (31), seguidas pelas anfíbias e emergentes (9), somente emergentes (7) e submersas fixas (5).

Outros estudos com macrófitas aquáticas também registraram uma maior riqueza de espécies anfíbias (Irgang \& Gastal Jr. 1996; Matias et al. 2003; Paz \& Bove 2007). Geralmente essas espécies estão associadas a ambientes sujeitos aos pulsos de inundações sazonais (Costa Neto et al. 2007). A variação do nível de água modificou constantemente a margem da Lagoa da Restinga do Massiambu, favorecendo a maior ocorrência de espécies adaptadas tanto ao meio aquático quanto ao terrestre (anfíbia). Além disso, a predominância dessas formas biológicas pode estar relacionada à baixa profundidade e a sua resistência à diminuição do volume de água (Neves et al. 2006).

Segundo Irgang \& Gastal Jr (1996) as macrófitas aquáticas podem apresentar somente uma forma biológica (pura) ao longo de toda sua vida ou combinações de duas ou mais formas. Para a área de estudo, 48 espécies apresentaram formas biológicas puras e 15 foram reconhecidas em combinações de duas ou mais formas. Essas combinações refletem as adaptações das espécies à variação no nível de água da lagoa. Conforme Pott \& Pott (2000b), a condição do habitat, principalmente o nível de água, faz com que uma espécie apresente mais de uma forma biológica.

Algumas espécies terrestres permanecem inundadas durante períodos de intensa precipitação, como Stylosanthes viscosa, Desmodium adscendens e Tibouchina urvilleana, as quais podem ser consideradas como anfíbias ocasionais. Uma vez que, as anfíbias propriamente ditas são formas adaptadas a interface do ambiente aquático e terrestre, sendo tolerante a seca (Irgang \& Gastal Jr. 1996). Enquanto anfíbias ocasionais não são plantas adaptadas ao ambiente aquático, mas sim resistentes. Segundo Paz \& Bove (2007), a presença destas plantas não hidrófilas em ambientes úmidos ou aquáticos não significa dependência e sim, tolerância à água por um curto período, que pode ser conseqüência de inundações acidentais ou pelo avanço vegetativo durante uma estação de estiagem.

O estudo demonstra o domínio de táxons adaptados às variações do nível de água na lagoa. Além disso, essas variações promovem alterações no biótopo, fazendo com que algumas espécies apresentem combinações de diferentes formas biológicas.

Das 63 espécies presentes na lagoa, 33 foram registradas no estudo quantitativo (Tab. 2). Destacam-se as espécies anfíbias e emergentes Enydra sessilis $(\mathrm{CR}=19,27 \% ; \mathrm{FR}=13,48 \%) \mathrm{e}$ Luziola peruviana $(\mathrm{CR}=9,95 \% ; \mathrm{FR}=10,6 \%)$, com a maior cobertura e freqüência, e dentre as submersas fixas, Chara zeylanica $(\mathrm{CR}=9,91 \%$; $\mathrm{FR}=5,77 \%)$ e Potamogeton lucens $(\mathrm{CR}=8,79 \%$; $\mathrm{FR}=6,27 \%$ ).

A ordenação da DCA demonstra que muitas espécies tendem a ocupar regiões especificas da Lagoa da Restinga do Massiambu (Fig. 4). Os escores do eixo 1 foram significativamente correlacionados com nível de água dos quadros, confirmada pela análise de correlação de Spearman ( $r s=0.78 ; \mathrm{p}<0.0001)$. Verifica-se que as espécies estão distribuídas no ambiente de acordo com o gradiente de profundidade, sentido margem interior da lagoa (Fig. 4), à esquerda, preferencialmente anfíbias, como: Eleocharis minima, Echinodorus bolivianus, Eleocharis flavescens, Eleocharis nana, Lobelia nummularioides, Centella asiatica, Cladium jamaicense, Hydrocotyle verticillata, entre outras; ao centro, anfíbias e emergentes, como: Enydra sessilis e Bacopa monnieri; e, a direita, as submersas fixas Chara rusbyana e Potamogeton lucens.

A análise subjetiva das distâncias entre os pontos (espécies) na Figura 4, tomadas pelo seu grau de semelhança ou diferença (Kent \& Coker 1992), proporciona distinção de dois grupos. O primeiro, na parte inferior, com a distribuição de espécies mais próximas umas as outras, possivelmente por dividirem a mesma posição no espaço e apresentarem distribuição semelhante na cobertura vegetal; já que, espécies que ocorrem com exatamente a mesma abundância nos mesmos quadros, podem ocupar o mesmo ponto (Kent \& Coker 1992). A coexistência entre estas espécies pode ser permitida pelo uso de recursos repartidos através de diferentes formas biológicas (Keddy 1984), por exemplo, como na proximidade das espécies Utricularia gibba (anfíbia e epífita), Chara zeylanica (submersa fixa) e Polygonum punctatus (anfíbia e emergente). Segundo Grubb (1977) além da variação das formas biológicas, os recursos podem ser repartidos pelos rítmos fenológicos, flutuações do ambiente e por 
diferentes relações competitivas. O segundo grupo, parte superior da Figura 4, apresenta espécies entre pontos mais esparsos, que ocupam e/ou dominam regiões distintas na lagoa, como exemplo, Enydra sessilis com a maior cobertura vegetal na margem, $\mathrm{e}$ Potamogeton lucens e Chara rusbyana em regiões mais profundas.

A distribuição da cobertura das macrófitas aquáticas mais freqüentes na Lagoa da Restinga do Massiambu em função da profundidade de água são apresentadas nas Figuras 5a-b. As avaliações dos histogramas demonstram que as espécies possuem uma amplitude de ocorrência espacial em relação ao nível da água, tendendo a desenvolver sua cobertura em profundidades preferenciais, que segundo Fernández-Aláez et al. (1999) é representada pelos valores mais altos. A extensão da amplitude de ocorrência de uma dada espécie pode ser considerada como uma medida de ocupação do seu nicho (Keddy 1983, 1984).

Enydra sessilis ocorre em até $60 \mathrm{~cm}$ de profundidade, entretanto, apresenta maior desenvolvimento de sua cobertura entre níveis de água de 0 a $15 \mathrm{~cm}$. Luziola peruviana e Eleocharis nana possuem o mesmo padrão, demonstrando que estas espécies se desenvolvem preferencialmente em regiões de interface entre o ambiente aquático e terrestre, fortalecendo sua classificação como anfíbias.

Nymphoides indica apresenta maior cobertura entre 15 a $20 \mathrm{~cm}$ de água. Esta espécie é referida por diversos autores como flutuante fixa (Esteves 1998; Pott \& Pott 2000a; 2000b; Souza \& Lorenzi 2008), sendo sua família representada por vegetais exclusivamente aquáticos (Cook et al. 1974). No entanto, no estudo pode ser encontrada em solos encharcados (nível de água $=0$ ) vindo a demonstrar sua plasticidade, combinando formas biológicas de flutuante fixa e anfíbia.

Bacopa monnieri, Lilaeopsis attenuata, Eleocharis flavescens e Ludwigia peploides ocorrem até o nível de $45 \mathrm{~cm}$ de água, Polygonum punctatus é registrado até $70 \mathrm{~cm}$ de água, porém ambas apresentam melhor desenvolvimento tanto como anfíbias, quanto emergentes. L. peploides comportando-se também como flutuante, vegetando entre 35 a $45 \mathrm{~cm}$ de água. Bidens laevis ocorre na margem da lagoa com profundidade preferencial entre 15 e $20 \mathrm{~cm}$, sendo classificada como emergente em águas rasas.
Utricularia gibba vegeta desde solos úmidos até $60 \mathrm{~cm}$ de profundidade, sendo frequentemente encontrada como anfíbia e epífita. Essas informações acrescentam novas formas biológicas para a espécie, anteriormente referida somente como submersa livre ou flutuante (Irgang \& Gastal Jr. 1996; Pott \& Pott 2000b). Além disso, ocorre com maior cobertura de 15 a

Tabela 2 - Relação de espécies, códigos, cobertura (CR) e frequência relativa (FR) das macrófitas aquáticas reconhecidas na amostragem da estrutura e composição da comunidade na Lagoa de Massiambu.

Table 2 - List of species, codes, relative cover (CR) and frequencies (FR) of sampling macrophytes recognized in the structure and composition of the community from the Massiambu Lake.

\begin{tabular}{lll}
\hline Espécie & $\mathbf{C R}(\boldsymbol{\%})$ & $\mathbf{F R}(\boldsymbol{\%})$ \\
\hline Enydra sessilis & 19,27 & 13,48 \\
Luziola peruviana & 9,95 & 10,60 \\
Nymphoides indica & 5,83 & 7,08 \\
Potamogeton lucens & 8,79 & 6,27 \\
Bacopa monnieri & 4,18 & 6,27 \\
Eleocharis nana & 5,24 & 6,08 \\
Chara zeylanica & 9,91 & 5,77 \\
Eleocharis flavescens & 6,70 & 5,33 \\
Lilaeopsis attenuata & 1,46 & 4,01 \\
Chara rusbyana & 7,28 & 3,95 \\
Utricularia gibba & 1,46 & 3,26 \\
Polygonum punctatum & 2,41 & 3,20 \\
Bidens laevis & 3,56 & 2,63 \\
Potamogeton pectinatus & 2,37 & 2,63 \\
Ludwigia peploides & 1,51 & 2,63 \\
Panicum polygonatum & 1,18 & 2,38 \\
Eleocharis minima & 2,94 & 2,32 \\
Hyptis brevipes & 0,92 & 2,19 \\
Mayacafluviatilis & 0,45 & 1,76 \\
Lobelia nummularioides & 0,71 & 1,57 \\
Lindernia rotundifolia & 0,49 & 1,25 \\
Polygonum persicarioides & 0,81 & 1,19 \\
Hydrocotyle verticillata & 0,50 & 1,00 \\
Diodia saponariifolia & 1,03 & 0,88 \\
Azolla filiculoides & 0,08 & 0,56 \\
Centella asiatica & 0,15 & 0,50 \\
Polygonum porturiquensis & 0,46 & 0,44 \\
Ludwigia lagunae & 0,22 & 0,38 \\
Chara guairensi & 0,11 & 0,13 \\
Echinodorus bolivianus & 0,01 & 0,13 \\
Cladium jamaicense & 0,01 & 0,06 \\
Panicum schwackeanum & 0,01 & 0,06 \\
Totais & 100 & 100 \\
\hline & & \\
\end{tabular}




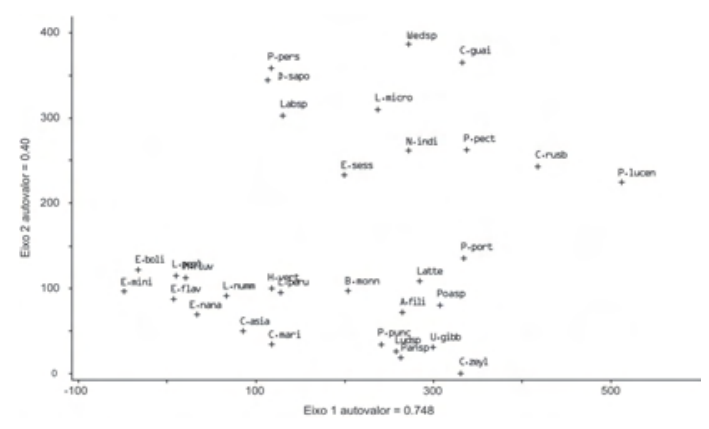

Figura 4 - Ordenação das espécies de macrófitas aquáticas pela DCA a partir dos escores de cobertura vegetal por parcela amostrada na Lagoa de Massiambu. A.fili (Azolla filiculoides); B.monn (Bacopa monnieri); C.asia (Centella asiatica); C.guai (Chara guaiensis); C.mari (Cladium mariscus); C.rusb (Chara rusbyana); C.zeyl (Chara zeylanica); D.sapo (Diodia saponariifolia); E.boli (Echinodorus bolivianus); E.flav (Eleocharis flavescens); E.mini (Eleocharis minima); E.nana (Eleocharis nana); E.sess (Enhydra sessilis); H.vert (Hydrocotyle verticillata); L.atte (Lilaeopsis attenuata); L.micro (Lindernia rotundifolia; L.numm (Lobelia nummularioides); L.pepl (Ludwigia peploides); L.peru (Luziola peruviana); Labsp (Hyptis brevipes); Ludsp (Ludwigia lagunae); M.fluv (Mayaca fluviatilis); N.indi (Nymphoides indica); P.lucen (Potamogeton lucens); P.pect (Potamogeton pectinatus); P.pers (Polygonum persicariodes); P.port (Polygonum portoricense); P.punc (Polygonum punctatun); Pansp (Panicum schwackeanum); Poasp (Panicum polygonatum); U.gibb (Utricularia gibba); Wedsp (Bidens laevis).

Figure 4 - Ordination of the species of aquatic macrophytes by the DCA from scores of vegetation cover per plot sampled on the Massiambu Lake.

$20 \mathrm{~cm}$ de água, convergindo com a preferência de muitas espécies registradas no estudo, as quais servem de suporte para o seu desenvolvimento.

Das macrófitas aquáticas submersas, Chara rusbyana, C. zeylanica, Potamogeton. lucens, e $P$. pectinatus apresentam diferentes amplitudes de ocorrência nas áreas amostradas. Essas espécies foram encontradas em níveis de água que variaram de 5 até $95 \mathrm{~cm}$, entretanto, $P$. pectinatus não ultrapassou a profundidades de $50 \mathrm{~cm}$.

Em lagos temperados, Potamogeton pectinatus domina regiões rasas, especialmente sob condições de turbidez, chegando a formar densos agrupamentos em profundidades de 30 a $70 \mathrm{~cm}$ de água (Van den Berg et al. 2003; Istvánovics et al. 2008). P. lucens apresentou melhor desenvolvimento de sua cobertura em profundidades de 40 a $45 \mathrm{~cm}$ na lagoa, diferente do observado para lagos temperados onde sua condição ótima ocorre em águas relativamente profundas de 50 a $200 \mathrm{~cm}$ (Van Geest et al. 2005). Dentro da amplitude de ocorrência de Chara rusbyana, $C$. zeylanica e $P$. pectinatus foram verificados um desenvolvimento preferencial em duas ou mais zonas de profundidades. C. zeylanica e $C$. rusbyana apresentam as maiores cobertura de 15 a $20 \mathrm{~cm}$ e de 40 a $45 \mathrm{~cm}$ de água, respectivamente. A primeira co-ocorre com profundidades preferências de plantas de diferentes formas biológicas, enquanto a segunda vegeta preferencialmente com macrófitas submersas. Já $P$. pectinatus, desenvolve maior cobertura em regiões frequentemente ocupadas por macrófitas anfíbias e emergentes, entre 5 a $10 \mathrm{~cm}$ e 20 a $30 \mathrm{~cm}$ profundidades.

A distribuição da composição das macrófitas aquáticas também apresentou um padrão em relação ao gradiente de profundidade, representado pela disposição das espécies no sentido margem-interior da lagoa. Esse padrão também pode ser utilizado para descrever a distribuição das formas biológicas apresentada por diversos autores (Pott et al. 1989; Pedralli \& Gonçalves 1997; Esteves 1998a; Pott \& Pott 2000b). Além disso, as espécies possuem uma amplitude de ocorrência espacial, tendendo a desenvolver maior cobertura em profundidades preferenciais, denominados aqui como "ponto ótimo".

A distribuição da composição e a classificação das formas biológicas das macrófitas aquáticas descreveram os padrões espaciais encontrados para a Lagoa da Restinga do Massiambu, os quais podem ser corroborados em outros estudos de ambientes lacustres de águas rasas. Todavia, estudos temporais podem trazer novas contribuições para o entendimento da dinâmica desses ecossistemas.

\section{Agradecimentos}

Os autores agradecem a FATMA pela licença para o desenvolvimento do trabalho na área. $\mathrm{O}$ primeiro autor agradece à Capes a bolsa concedida durante o desenvolvimento do trabalho de mestrado junto ao Programa de Pós-Graduação em Biologia Vegetal/UFSC. 

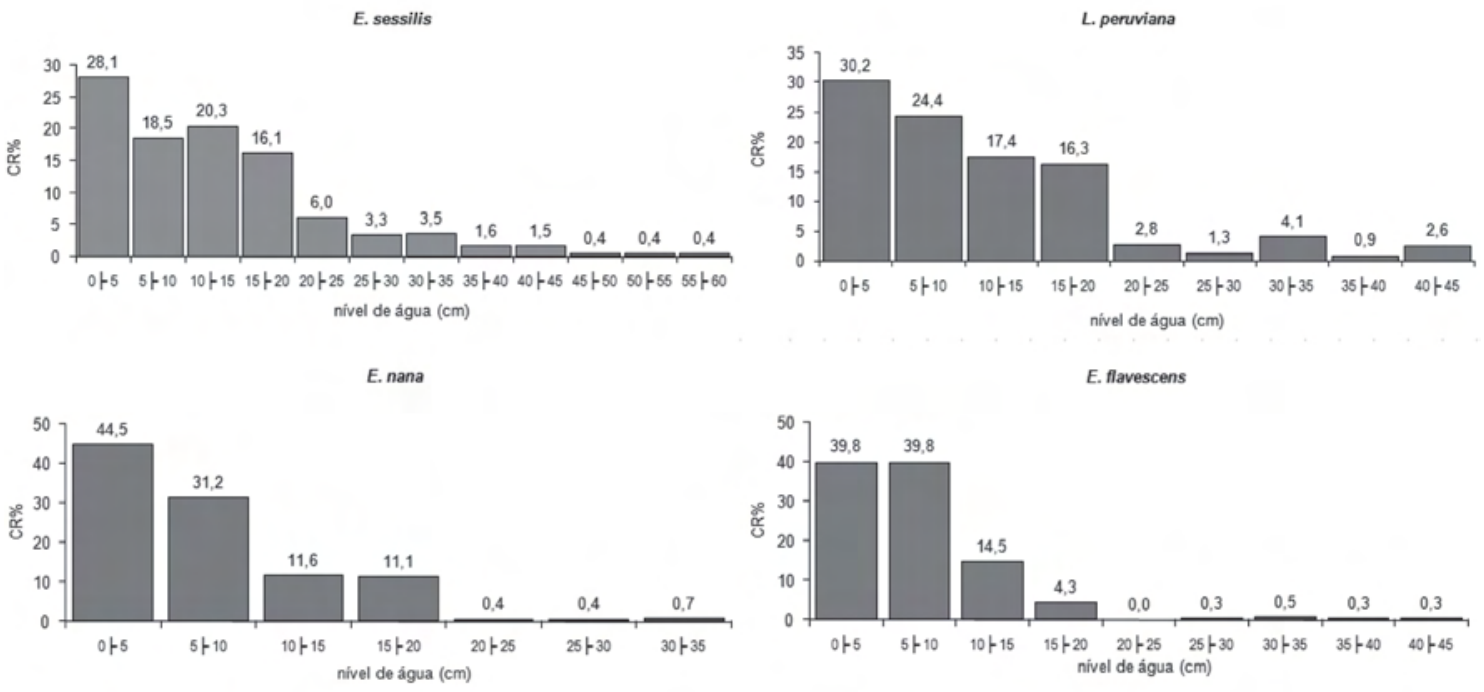

N. indica
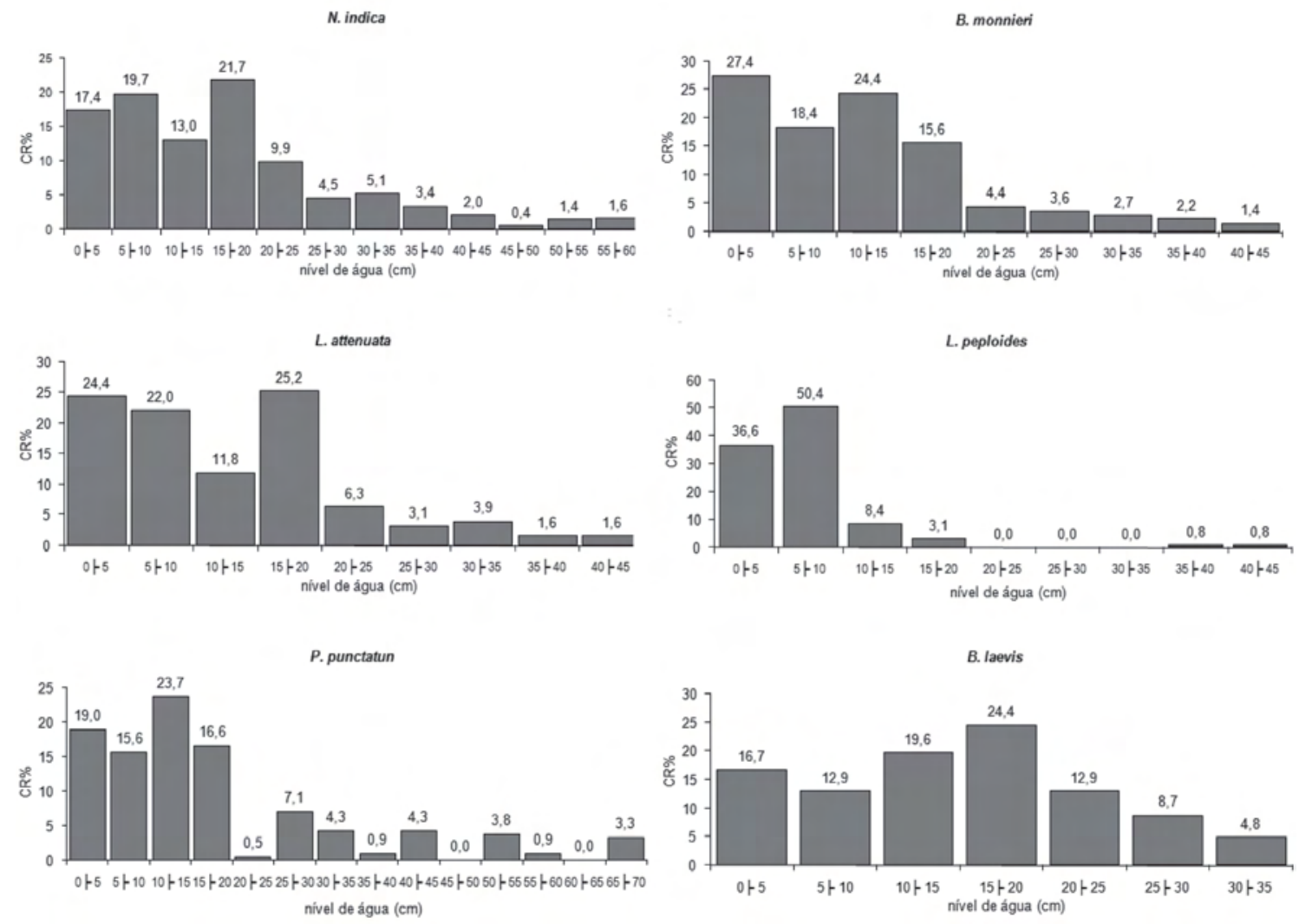

Figura 5a - Distribuição da cobertura relativa das espécies mais frequentes por zona de profundidade de água na Lagoa da Restinga do Massiambu.

Figure 5a - Distribution of the relative cover on the most frequent species by depth water zone in the Lake Restinga of the Massiambu. 

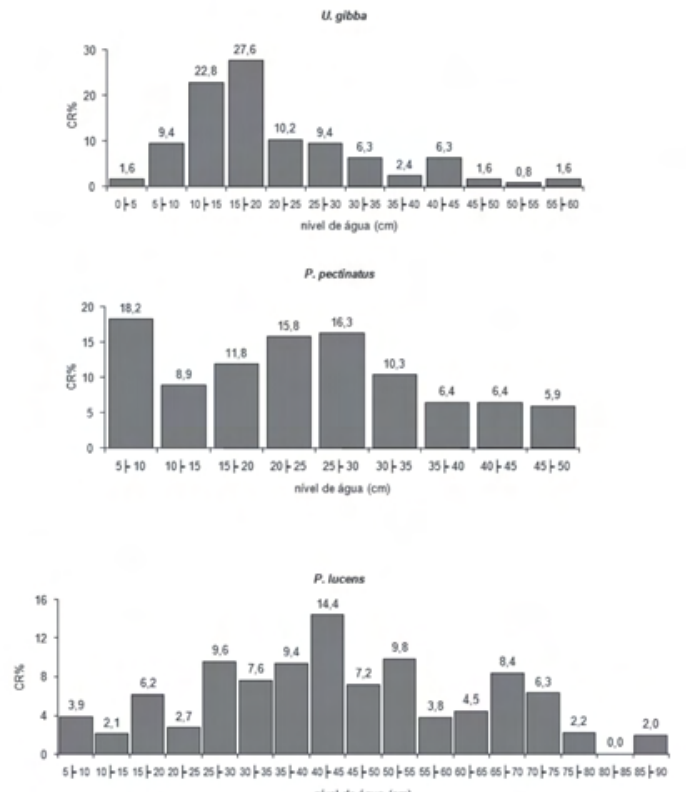
nivel do agua (cm)
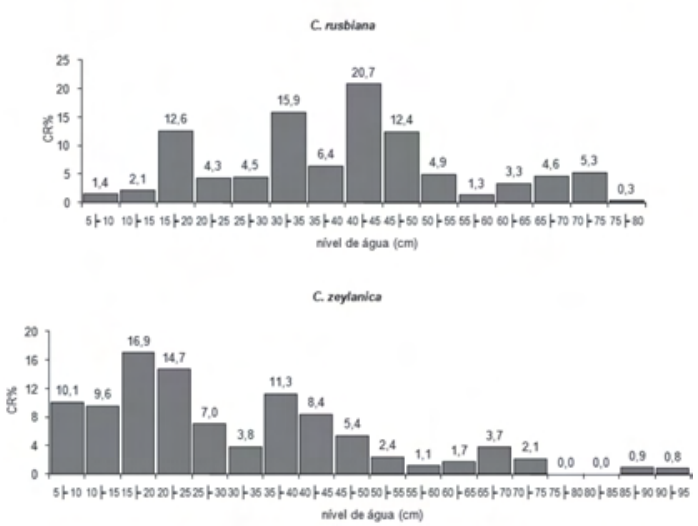

Figura 5b - Distribuição da cobertura relativa das espécies mais frequentes por zona de profundidade de água na Lagoa da Restinga do Massiambu.

Figure $\mathbf{5 b}$ - Distribution of the relative cover on the most frequent species by depth water zone in the Lake Restinga of the Massiambu.

\section{Referências}

Albuquerque, B.W.P. 1981. Plantas forrageiras da Amazônia I. Aquáticas flutuantes livres. Acta Amazonica 11: 457-471.

Amaral, M.C.E.; Bittrich, V.; Faria, A.D.; Anderson, L.O. \& Aona, L.Y.S. 2008. Guia de campo para plantas aquáticas e palustres do estado de São Paulo. Holos Ed., Ribeirão Preto. 452p.

APG III - Angiosperm Phylogeny Group. 2009. An update of the Angiosperm Phylogeny Group classification for the orders and families of flowering plants: APG III. Botanical Journal of the Linnean Society 161: 105-121.

Araujo, A.; Bueno, N.C.; Meurer, T. \& Bicudo, C.E.M. 2010. Charophyceae. In: Forzza, R.C. et al. Lista de espécies da flora do Braisl. Jardim Botânico do Rio de Janeiro. Disponível em < http://floradobrasil. jbrj.gov.br/2010/FB119576>. Acesso em 5 Ago 2011.

Ayres, M.; Ayres Jr, M.; Ayres D.L. \& Santos, A.A.S. 2007. Bioestat 5.0: aplicações estatísticas nas áreas das ciências biológicas e médicas. Sociedade Civil Mamirauá, Belém. 380p.

Bannister, P. 1966. The use of subjective estimates of cover-abundance as the basis for ordination. The Journal of Ecology 54: 665-674.

Barreto, C.C. 1999. Heterogeneidade espacial do habitat e diversidade específica: implicações ecológicas e métodos de mensuração. Série Oecologia Brasiliensis 7: 121-153.

Bicudo, R.M.T. 1972. O gênero Chara (Charophyceae) no Brasil. Tese de Doutorado. Universidade de São Paulo, São Paulo. 229p.

Bicudo, R.M.T. 1974. O gênero Chara (Charophyceae) no Brasil, 1: subseção Willdenowia R.D.Wood. Rickia 6: 127-189.

Bove, C.P.; Gil, A.S.B.; Moreira, C.B. \& Anjos, R.S. 2003. Hidrófitas fanerogâmicas de ecossistemas aquáticos temporários da planície costeira do estado do Rio de Janeiro, Brasil. Acta Botanica Brasilica 17: 119-135.

Braun-Blanquet, J. 1979. Fitosociologia: bases para el estudio de las comunidades vegetales. H. Blume Ediciones, Madrid. 820p.

Bueno, N.C.; Bicudo, C.E.M.; Picelli-Vicentim, M.M. \& Ishii, I.I. 1996. Characeae (Charophyceae) do Pantanal de Mato Grosso do Sul, Brasil: Chara. Hoehnea 23: 21-34.

Bueno, N.C.; Bicudo, C.E.M.; Biolo, S. \& Meurer, T. 2009. Levantamento florístico das Characeae (Chlorophyta) de Mato Grosso e Mato Grosso do Sul, Brasil: Chara. Revista Brasileira de Botânica 32: 759-774.

Collot, D.; Koriyama, F. \& Garcia, E. 1983. Repartitions, biomasses et productions des macrophytes du lac Titicaca. Revue D' Hydrobiologie Tropicale 16: 241-261.

Cook, C.D.K.; Gut, B.J.; Rix, E.M.; Schneller, J. \& Seitz, M. 1974. Water plants of the world: A manual for the identification of the genera of freshwater macrophytes. Dr. W. Junk, Publishers, The Hague. $561 \mathrm{p}$.

Costa Neto, S.V.; Senna, C.S.F.; Tostes L.C.L. \& Silva, S.R.M. 2007. Macrófitas aquáticas das Regiões dos Lagos do Amapá, Brasil. Revista Brasileira de Biociências 5: 618-620.

Costa Neto, S.V.; Tostes L.C.L. \& Thomaz, D.O. 2003. Inventário Florístico das Ressacas das Bacias do Igarapé da Fortaleza e do Rio Curiaú. In: Takiyama, L.R. \& Silva, A.Q. (orgs.). Diagnóstico das ressacas do estado 
do Amapá: bacias do Igarapé da Fortaleza e Rio Curiaú, Macapá-AP. CPAQ/IEPA, DGEO/SEMA. Pp. 1-22.

Duarte C.M. \& Kalff, J. 1986. Littoral slope as a predictor of the maximum biomass of submerged macrophyte communities. American Society Limnology and Oceanography 31: 1072-1080.

Esteves, F.A. 1998a. Fundamentos de limnologia. Interciência/FINEP, Rio de Janeiro. 602p.

Esteves, F.A. 1998b. Lagoas costeiras: origem, funcionamento e possibilidade de manejo. In: Esteves, F.A. (ed.). Ecologia das lagoas costeiras do Parque Nacional da Restinga de Jurubatiba e do Município de Macaé. UFRJ, Rio de Janeiro. Pp. 63-87.

Falkenberg, D.B. 1999. Aspectos da flora e da vegetação secundária da restinga de Santa Catarina, Sul do Brasil. Ínsula 28: 01-29.

Fernández-Aláez, C.; Fernández-Aláez; M. \& Bécares, E. 1999. Influence of water level fluctuation on the structure and composition of the macrophyte vegetation in two small temporary lakes in the northwest of Spain. Hydrobiologia 415: 155-162.

Fernández-Aláez, M.; Calabuig E.L. \& Fernández-Aláez, M. C. 1986. Estudio sobre la vegetacion macrofitica en tres lagunas del sureste de la provincia de Leon. Limnética 2: 41-49.

Ferreira, F.A.; Mormul, R.P.; Pedralli, G.; Pott, V.J. \& Pott, A. 2010. Estrutura da comunidade de macrófitas aquáticas em três lagoas do Parque Estadual do Rio Doce, Minas Gerais, Brasil. Hoehnea 37: 43-52.

Fortney, R.H.; Benedict, M.; Gottgens, J.F.; Walters, T.L.; Leady B.S. \& Rentch, J. 2004. Aquatic plant community composition and distribution along an inundation gradient at two ecologically-distinct sites in the Pantanal region of Brazil. Wetlands Ecology and Management 12: 575-585.

França F.; Melo, E.; Neto, A.G.; Araújo, D.; Bezerra, M.G.; Ramos, H.M.; Castro, I. \& Gomes, D. 2003. Flora vascular de açudes de uma região do semi-árido da Bahia, Brasil. Acta Botanica Brasilica 17: 549-559.

Goetghebeur, P. 1998. Cyperaceae. In: Kubitzki, K. (ed.). The families and genera of vascular plants. Springer, Berlin. Pp. 141-190.

Grubb, P.J. 1977. The maintenance of species richness in plant communities: the importance of the regeneration niche. Biological Reviews 52: 107-145.

Guglieri, A. \& Longhi-Wagner, H.M. 2000. Gramineae: Panicum. Flora Ilustrada do Rio Grande do Sul. Boletim do Instituto de Biociências 50: 1-110.

Irgang, B.E. \& Gastal Jr., C.V.S. 1996. Plantas aquáticas da planície costeira do Rio Grande do Sul. UFRGS, Porto Alegre. 290p.

Irgang, B.E.; Pedralli, G. \& Waechter, J.L. 1984. Macrófitos aquáticos da Estação Ecológica do Taim, Rio Grande do Sul, Brasil. Roessleria 6: 395-404.

Istvánovics, V.; Honti, M.; Kovács, A. \& Osztoics, A. 2008. Distribution of submerged macrophytes along environmental gradients in large, shallow Lake Balaton (Hungary). Aquatic Botany 88: 317-330.

Keddy, P.A. 1983. Shoreline vegetation in Axe Lake, Ontario: Effects of exposure on zonation patterns. Ecology 64: 331-344.

Keddy, P.A. 1984. Plant zonation on lakeshores in Nova Scotia: A test of the resource specialization hypothesis. Journal of Ecology 72: 797-808.

Kent, M. \& Coker, P. 1992. Vegetation description and analysis: a practical approach. Belhaven Press, London. 363p.

Kita, K.K. \& Souza, M.C. 2003. Levantamento florístico e fitofisionomia da lagoa da Figueira e seu entorno, planície alagável do alto rio Paraná, Porto Rico, Estado do Paraná, Brasil. Acta Scientiarum: Biological Sciences 25: 145-155.

Klein, R.M. 1996. Espécies raras ou ameaçadas de extinção do Estado de Santa Catarina. vol. 2. IBGE, Rio de Janeiro. 170p.

Kovacs, W.L. 1999. MVSP - A multivariate statistical package for windows, ver. 3.1. Kovach Computing Services, Pentraeth. 133p.

Krebs, C.J. 1998. Ecological Methodology. Addison Wesley Longman, Menlo Park. 620p.

Maltchik, L.; Rolon A.S. \& Schott, P. 2007. Effects of hydrological variation on the aquatic plant community in a floodplain palustrine wetland of southern Brazil. Limnology 8: 23-28.

Matias L.Q.; Amado E.R. \& Nunes, E.P. 2003. Macrófitas aquáticas da Lagoa Jijoca de Jericoacoara, Ceará, Brasil. Acta Botanica Brasilica 17: 623-623.

McCune, B. \& Mefford, M.J. 1999. Multivariate analysis of ecological data. Version 4.01. MjM Software, Gleneden Beach.

Mondin, C.A. 2004. Levantamento da tribo Heliantheae Cass. (Asteraceae), sensu stricto no Rio Grande do Sul, Brasil. Tese de Doutorado. UFRGS, Porto Alegre. 353p.

Neves, E.L.; Leite, K.R.B.; França, F. \& Melo, E. 2006. Plantas aquáticas vasculares em uma lagoa de planície costeira no município de Candeias, Bahia, Brasil. Sitientibus Série Ciências Biologicas 6: 24-29.

Pakarinen, P. 1984. Cover estimation and sampling of boreal vegetation in Northern Europe. In: Knapp R. (ed.). Sampling methods and taxon analysis in vegetation science. Handbook of vegetation science, part 4. Dr. W. Junk Publishers, The Hague. Pp. 33-44.

Paz, J. \& Bove, C.P. 2007. Hidrófitas vasculares da lagoa de Carapebus, Parque Nacional da Restinga de Jurubatiba, Rio de Janeiro, Brasil. Revista Brasileira de Biociências 5: 495-497.

Pedralli, G. \& Gonçalves, A.P.S. 1997. Levantamento florístico e aspectos da sucessão em duas lagoas da região cárstica de Minas Gerais, Brasil. Daphne 7: 17-25.

Peet, R.K. 1974. The measurement of species diversity. Annual Review of Ecology and Systematics 5: 285-307. 
Picelli-Vicentim, M.M.; Bicudo, C.E.M. \& Bueno, N.C. 2004. Flora ficológica do estado de São Paulo, 5 Charophyceae. RiMa, São Carlos. 124p.

Pilz, A.B.F. \& Pereira, A.B. 1988. Polygonum L. no Rio Grande do Sul. Pesquisas 38: 43-47.

Pivari, M.O.D.; Salimena, F.R.G.; Pott, V.J. \& Pott, A. 2008. Macrófitas aquáticas da Lagoa Silvana, Vale do Rio Doce, Minas Gerais, Brasil. Iheringia, série Botânica 63: 321-327.

Pompêo, M.L.M. \& Moschinhi-Carlos, V. 2003. Macrófitas aquáticas e perifítion, aspectos ecológicos e metodológicos. RiMa, São Carlos. 124p.

Pott, A. \& Pott, V.J. 2003. Dinâmica da vegetação aquática do Pantanal. In: Thomaz, S.M. \& Bini, L.M. (org.). Ecologia e manejo de macrófitas aquáticas. EDUEM, Maringá. Pp. 145-162.

Pott, A. \& Pott, V.J. 2000b. Plantas aquáticas do Pantanal. Embrapa, Brasília. 320p.

Pott, V.J. \& Pott, A. 2000a. Distribuição das macrófitas aquáticas no Pantanal. In: Anais do III Simpósio sobre recursos Naturais e Sócio-Econômicos do Pantanal - Os desafios do novo milênio. EmbrapaPantanal. Pp. 1-26.

Pott, V.J.; Bueno, N.C. \& Silva, M.P. 1992. Levantamento florístico e fitossociológico de macrófitas aquáticas em lagoas da Fazenda Leque, Pantanal, MS. In: Anais do VIII Congresso da Sociedade de Botânica de São Paulo. SBSP, Campinas. Pp. 91-99.

Pott, V.J.; Bueno, N.C.; Pereira, R.A.C.; Salis, S.M. \& Vieira, N.L. 1989. Distribuição de macrófitas aquáticas numa lagoa na fazenda Nhumirim, Nhecolândia, Pantanal, MS. Acta Botanica Brasilica 3: 153-168.

Prado, J.F. 2003. Characeae do Rio Grande do Sul, Brasil. Tese de Doutorado. Universidade Federal do Rio Grande do Sul, Porto Alegre. 232p.

Rambo, B. 1949. Estudos botânicos em Sombrio, município de Araranguá, Santa Catarina. In: Anais Botânicos do Herbário Barbosa Rodrigues. Vol. 1. Herbário Barbosa Rodrigues, Itajaí. Pp. 8-20.

Rebellato, L. \& Nunes da Cunha, C. 2005. Efeito do "fluxo sazonal mínimo da inundação" sobre a composição e estrutura de um campo inundável no Pantanal de Poconé, MT, Brasil. Acta Botanica Brasilica 19: 789-799.

Reitz, P.R. 1961. Vegetação da zona marítima de Santa Catarina. Sellowia 13: 17-115.

Rocha, C.G.; Resende U.M. \& Lugnani, J.S. 2007. Diversidade de macrófitas em ambientes aquáticos do IPPAN na Fazenda Santa Emília, Aquidauana, MS. Revista Brasileira de Biociências 5: 456-458.

Rodriguez, W.A. 1964. Novas Characeae na região Amazônica. Ciência e Cultura 16: 154.

Rolon, A.S. \& Maltchik, L. 2006. Environmental factors as predictors of aquatic macrophyte richness and composition in wetlands of Southern Brazil. Hydrobiologia 556: 221-231.
Santa Catarina. 2009. Lei Estadual n ${ }^{\circ} 14.661$, de 26 de março de 2009. Reavalia e define os atuais limites do Parque Estadual da Serra do Tabuleiro, criado pelo Decreto $\mathrm{n}^{\circ} 1.260$, de $1^{\circ}$ de novembro de 1975 , e retificado pelo Decreto $\mathrm{n}^{\circ} 17.720$, de 25 de agosto de 1982, institui o Mosaico de Unidades de Conservação da Serra do Tabuleiro e Terras de Massiambu, cria o Fundo Especial de Regularização, Implementação e Manutenção do Mosaico - FEUC, e adota outras providências. Disponível em $<\mathrm{http}$ :/ /www.mp.sc.gov.br/portal/site/conteudo/ normas_legais/estadual/leis/le_14661_2009.doc>. Acesso em 30 Jul 2011.

Santos, A.M. \& Thomaz, S.M. 2007. Aquatic macrophytes diversity in lagoons of a tropical floodplain: the role of connectivity and water level. Austral Ecology 32: 177-190.

Souza, D.C.; Thomaz S.M. \& Bini, L.M. 2002. Species richness and beta-diversity of aquatic macrophytes assemblages in three floodplain tropical lagoons: evaluating the effects of sampling size and depth gradients. Amazoniana 17: 213-225.

Souza, V.C. \& Lorenzi, H. 2008. Botânica sistemática: guia ilustrado para identificação das famílias de Angiospermas da flora brasileira, baseado em APG II. Instituto Plantarum, Nova Odessa. 640p.

Souza, V.C. \& Giulietti, A.M. 2009. Levantamento das espécies de Scrophulariaceae sensu lato nativas do Brasil. Pesquisas 60: 1-288.

Spence, D.H.N. 1982. The zonation of plants in freshwater lakes. Advanced Ecology Research 12: 37-125.

Tavares, A.S.; Araújo A.C. \& Guimarães, F.B. 2007. Cyperaceae ocorrentes na Baixada do Maciambú, Parque Estadual da Serra do Tabuleiro, Palhoça, SC. Revista Brasileira de Biociências 5: 186-188.

Thomaz, S.M. 2005. Fatores que afetam a distribuição e o desenvolvimento de macrófitas aquáticas em reservatórios: uma análise em diferentes escalas. In: Nogueira, M.G.; Jorcin, A. \& Henry, R. (eds.). Ecologia de reservatórios: impactos potenciais, ações de manejo e sistemas de cascata. RiMa, São Carlos. Pp. 165-181.

Thomaz, S.M. \& Bini, L.M. 2003. Análise crítica dos estudos sobre macrófitas aquáticas desenvolvidos no Brasil. In: Thomaz, S.M. \& Bini, L.M. (eds.). Ecologia e manejo de macrófitas aquáticas. Eduem, Maringá. Pp. 19-38.

Thomaz, S.M.; Pagioro, T.A.; Bini, L.M. \& Roberto, M.C. 2005. Ocorrência e distribuição espacial de macrófitas aquáticas em reservatórios. In: Rodrigues, L.; Thomaz, S.M.; Agostinho, A.A. \& Gomes, L. C. (org.). Biocenoses em reservatórios: padrões espaciais e temporais. RiMa, São Carlos. Pp. 281-292.

Thomaz, S.M.; Pagioro, T.A.; Bini L.M. \& Souza, D.C. 2002. Macrófitas aquáticas da planície de Inundação do Alto rio Paraná: listagem de espécies e padrões de diversidade em ampla escala. PELD, Relatório Anual 
2002. Disponível em <http://www.peld.uem.br/ Relat2002/pdf/comp_biotico_macrofitas.pdf>. Acesso em 15 Jul 2011.

Trevisan, R. \& Boldrini, I.I. 2008. O gênero Eleocharis R. Br. (Cyperaceae) no Rio Grande do Sul, Brasil. Revista Brasileira de Biociências 6: 7-67.

Tryon, R.M. \& Tryon, A.F. 1982. Ferns and allied plants: with special reference to tropical America. Springer Verlag, New York. 857p.

Van den Berg, M.S.; Joosse, W. \& Coops, H. 2003. A statistical model predicting the occurrence and dynamics of submerged macrophytes in shallow lakes in the Netherlands. Hydrobiologia 506-509: 611-623.

Van Geest, G.H.; Coops, H.; Roijackers, R.M.M.; Buijse A.D. \& Scheffer, M. 2005. Succession of aquatic vegetation driven by reduced water-level fluctuation in floodplain lakes. Journal of Applied Ecology 42: 251-260.

Vieira Jr., J.; Nechhi Jr., O.; Branco, C.C.Z. \& Branco, L.H.Z. 2003. Characeae (Chlorophyta) em ecossistemas lóticos do estado de São Paulo, Brasil: Chara e distribuição ecológica. Hoehnea 30: 53-70.

Walker, I.; Miyai R. \&. Melo, M.D.A. 1999. Observations on aquatic macrophyte dynamics in the Reservoir of Baldina Hydroelectric powerplant, Amazonas State, Brazil. Acta Amazonica 29: 243-266.

Wood, R.D. \& Imahori, K. 1964. A revision of the Characeae. 2: iconograph of the Characeae. J. Cramer, Weinheim. 797p.

Wood, R.D. \& Imahori, K. 1965. A revision of the Characeae. 1: monograph of the Characeae. J. Cramer, Weinheim. 904p. 